JURNAL PUBLIPRENEUR: POLITEKNIK NEGERI MEDIA KREATIF Vol.6, No. 1, Juni 2018, Doi: https://doi.org/.xxxxx, hal. 18-25

\title{
ANALISA PENDAPATAN ORANG TUA SISWA POLITEKNIK NEGERI MEDIA KREATIF DENGAN FUZZY LOGIC
}

\author{
Yusuf Nurrachman \\ Program Studi Desain Grafis, Jurusan Desain Grafis, Politeknik Negeri Media Kreatif, Jakarta, \\ Indonesia 12640 \\ Email : yusuf@polimedia.ac.id
}

\begin{abstract}
ABSTRAK
Semakin berkembangnya sebuah institusi dalam hal ini Politeknik Negeri Media Kreatif tidak lepas dari pemasukan pembayaran uang kuliah mahasiswa yang digunakan untuk membiayai berbagai hal yang berhubungan dengan pembelajaran dan perlengkapan sarana prasarana. Pembayaran uang kuliah atau uang semesteran ini berhubungan dengan pendapatan orang tua siswa yang semenjak awal pendaftaran telah didata dan telah disanggupi untuk dipenuhi oleh pendaftar, tetapi dalam proses pembayaran semester sering terjadi keterlambatan pembayaran atau bahkan tidak sanggup membayar.

Dalam penelitian ini akan dilakukan analisis pendapatan orang tua siswa dengan fuzzy logic dengan melakukan pengumpulan data dari beberapa mahasiswa aktif yang saat ini masih berkuliah di Politeknik Negeri Media Kreatif. Fuzzy logic adalah merupakan salah satu cabang ilmu dalam Kecerdasan Buatan / artificial Intelligence yang pemanfaatannya sudah banyak digunakan di berbagai sektor industri. Hasil dari penelitian ini diharapkan kedepan dapat membantu Politeknik Negeri Media Kreatif dalam pengambilan keputusan untuk menentukan tingkat minimum pendapatan orang tua yang ingin menyekolahkan anaknya di Politeknik Negeri Media Kreatif.
\end{abstract}

Kata kunci: fuzzy, logic, artificial, intelligence

\section{PENDAHULUAN}

\subsection{Latar Belakang}

Politeknik Negeri Media

Kreatif sebagai institusi yang bergerak di bidang pendidikan dimana telah banyak menghasilkan putra-putri Indonesia yang berkarir di dunia industri sesuai dengan program studi yang telah mereka jalani selama berkuliah.

Dalam perkembangannya sebuah Politeknik tidak terlepas dari pembayaran uang kuliah semester mahasiswa yang digunakan untuk pengembangan pembelajaran dan sarana prasarana sehingga proses belajar mengajar dapat berjalan dengan baik dan mahasiswa sebagai salah satu stake holder dapat terlayani dengan baik sesuai dengan apa yang sudah dikeluarkan oleh orang tua mereka.

Dalam proses biaya atau uang kuliah tersebut kadang terjadi keterlambatan uang kuliah sampai dengan orang tua yang tidak mampu untuk membayar uang kuliah, hal ini sangat menarik untuk dikaji karena ketika pendaftaran perkuliahan sudah ada perjanjian untuk dapat membayar uang perkuliahan setiap semester dalam hal ini 
JURNAL PUBLIPRENEUR: POLITEKNIK NEGERI MEDIA KREATIF

Vol.6, No. 1, Juni 2018, Doi: https://doi.org/.xxxxx, hal. 18-25

mungkin ada faktor lainnya sehingga terjadi hal tersebut.

Diluar faktor yang mungkin menyebabkan kegagalan pembayaran uang kuliah tersebut, maka akan dilakukan penelitian mengenai pendapatan orang tua siswa yang akan dianalisis menggunakan fuzzy logic sehingga nantinya dapat ditentukan minimal pendapatan orang tua untuk dapat memasukkan anaknya ke Politeknk Negeri Media Kreatif sesuai dengan biaya persemester yang diwajibkan.

\subsection{Rumusan Masalah}

Rumusan masalah dari penelitian ini adalah sebagai berikut ;

1. Apakah dengan fuzzy logic dapat menganalisa pendapatan orang tua siswa sehingga dapat dijadikan sebuah acuan untuk menentukan besaran minimal pendapatan orang tua siswa agar dapat menyekolahkan anaknya di Poilteknik Negeri Media Kreatif

\subsection{Batasan Masalah}

Agar proses penelitian tidak meluas dan efisien, maka penulis membatasi masalah pada penelitian ini :

1. Penelitian ini menggunakan analisa dengan menggunakan Fuzzy Logic pada tahapan fuzzification tanpa menggunakan mesin inferensi.

2. Data yang diambil pada penelitian ini berasal dari mahasiswa aktif Politeknik Negeri Media Kreatif.

\subsection{Tujuan dan Sasaran}

Tujuan dari Penelitian ini adalah menganalisa sebuah permasalahan yang sering muncul dalam hal ini pembayaran perkuliahan dilihat dari sudut pandang pendapatan orang tua siswa dengan pendekatan kecerdasan buatan yaitu fuzzy logic. Dimana hasilnya dapat dijadikan sebuah acuan bagi Politeknik Negeri Media Kreatif dalam memfilter calon mahasiswa di awal pendaftaran terutama dari pendapatan orang tua.

Adapun sasarannya adalah menghasilkan sebuah acuan minimum pendapatan orang tua siswa yang dapat menyekolahkan anaknya di Politeknik Negeri Media Kreatif.

\subsection{Manfaat Penelitian}

Manfaat yang dapat diambil dari penelitian ini adalah adanya penedekatan analisis dengan keilmuan kecerdasan buatan dalam hal ini fuzzy logic yang nantinya dapat dikembangkan ke banyak variable dengan permasalahan yang sama maupun berbeda.

\subsection{Target Luaran}

Target yang ingin dicapai pada penelitian ini adalah adanya sebuah analisis dengan menggunakan kecerdasan buatan dengan fuzzy logic yang dapat menggambarkan kondisi / tingkat pendapatan orang tua mahasiswa yang saat ini masih aktif dan bisa menjadikan acuan bagi Politeknik Negeri Media Kreatif dalam 
JURNAL PUBLIPRENEUR: POLITEKNIK NEGERI MEDIA KREATIF Vol.6, No. 1, Juni 2018, Doi: https://doi.org/.xxxxx, hal. 18-25

menentukan seberapa besar minimal pendapatan orang tua untuk dapat menyekolahkan anaknya di Politeknik Media Kreatif.

\section{TINJAUAN PUSTAKA}

\subsection{Kecerdasan Buatan}

Kecerdasan buatan atau artificial intelligence adalah merupakan salah satu bagian dari ilmu computer yang membuat agar mesin (computer) dapat melakukan pekerjaan seperti dan sebaik yang dilakukan oleh manusia.

2.2 Kecerdasan buatan dari sudut pandang penelitian

2.2.1 Mundane Task

- Persepsi (vision \& speech)

- Bahasa alami (understanding, generation

$\&$ translation)

- Pemikiran yang bersifat common sense

- Robot control

2.2.2 Formal Task

- Permainan / Games

- Matematika (geometri, kalkulus integral, logika, pembuktian)

2.2.3 Expert Task

- Analisis finansial

- Analisis medical

- Analisis ilmu pengetahuan

\subsection{Fuzzy Logic}

Fuzzy logic atau logika fuzzy adalah suatu cara yang tepat untuk memetakan sesuatu ruang input kedalam suatu output, beberapa penulis juga menyebutkan bahwa fuzzy logic digunakan untuk menyelesaikan masalah yang didalamnya mempunyai ketidakpastian, kekurangan informasi, keraguan dan kebenaran yang bersifat sebagian.

\subsection{Sistem Fuzzy}

Beberapa hal yang ada dalam system fuzzy adalah :

\subsubsection{Variabel Fuzzy}

Variabel fuzzy merupakan variable yang hendak dibahas dalam suatu system system fuzzy, contoh : umur, temperature permintaan, dsb.

\subsubsection{Himpunan Fuzzy}

Himpunan fuzzy merupakan suatu grup yang mewakili suatu kondisi atau keadaan tertentu dalam suatu variable, dimana dalam himpunan fuzzi mempunyai 2 atribut yaitu

- Linguistik : yaitu penamaan suatu grup dengan bahasa alami, seperti : Muda, Parobaya, Tua.

Numeris, yaitu suatu nilai atau angka yang menunjukkan ukuran dari suatu variable seperti : 40, 25, $50 \mathrm{dsb}$ 
JURNAL PUBLIPRENEUR: POLITEKNIK NEGERI MEDIA KREATIF

Vol.6, No. 1, Juni 2018, Doi: https://doi.org/.xxxxx, hal. 18-25

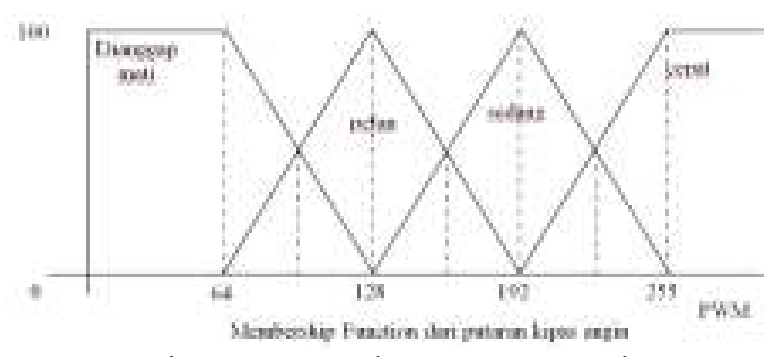

Gbr. 2.1 contoh representasi kurva

$$
\text { segitiga }
$$$$
\text { (sumber : }
$$

https:/ / electroniclib.files.wordpre ss.com/2010/07/putaran-

$$
\text { kipas.png) }
$$

2.4.1 Semesta Pembicaraan.

Semesta pembicaraan adalah

keseluruhan nilai yang

diperbolehkan untuk

dioperasikan dalam suatu variable fuzzy, semesta pembicaraan adalah variable bilangan real yang senantiasa naik dan monoton dari kiri ke kanan, bisa berupa postif maupun negative.

2.4.2 Domain

Domain himpunan fuzzy adalah keseluruhan nilai yang diijinkan dalam semesta pembicaraan dan boleh dioperasikan dalam suatu himpunan fuzzy . contoh :

$$
\begin{array}{ll}
\text { Muda } & =\left[\begin{array}{ll}
0 & 45
\end{array}\right] \\
\text { Parobaya } & =\left[\begin{array}{ll}
35 & 55
\end{array}\right] \\
\text { Tua } & =\left[\begin{array}{ll}
45 & \infty
\end{array}\right]
\end{array}
$$

\section{METODE PENELITIAN}

\subsection{Metode Penelitian}

Dalam proses penelitian ini penulis akan melakukan pengumpulan data dari mahasiswa Politeknik Negeri Media Kreatif yang selanjutnya akan dianalisa menggunakan fuzzy logic.

\subsection{Tahapan Penelitian}

3.2.1 Studi Literatur

Studi literature ini digunakan sebagai landasan dalam penggunaan aplikasi yang dijadikan sebagai alat untuk mengumpulkan data.

3.2.2 Perencanaan

Pada Tahapan ini penulis akan memulai melakukan perencanaan kapan dan dimana penelitian akan dilakukan serta objek penelitian .

3.2.3 Analisis

Pada tahapan ini penulis akan memulai melakukan analisa data yang sudah didapat dengan menggunakan tabulasi data , setelah itu dilakukan fuzzification, penentuan semesta pembicaraan dan domain dari himpunan fuzzy.

3.2.4 Implementasi

Tahapan Implementasi adalah merupakan hasil dari pengumpulan data dan diolah sesuai dengan kaidah - kaidah dan aturan dari metode yang digunakan.

\section{HASIL DAN PEMBAHASAN}

Dalam melakukan penelitian dibutuhkan data - data yang nantinya dapat dianalisa dan di proses menjadi sebuah informasi sesuai dengan tujuan yang diharapkan, dalam hal ini adalah melakukan Analisa pendapatan orang tua e-ISSN 2723-6323 p-ISSN 2338-5049 


\section{JURNAL PUBLIPRENEUR: POLITEKNIK NEGERI MEDIA KREATIF Vol.6, No. 1, Juni 2018, Doi: https://doi.org/.xxxxx, hal. 18-25}

siswa dengan fuzzy logic di Politeknik Negeri Media Kreatif.

\subsection{Pengumpulan Data}

Pada tahap pengumpulan data dilakukan penyebaran questioner kurang lebih 50 - 60 mahasiswa yang akan dijadikan data utama dalam penelitian selain itu juga dilakukan pencarian informasi mengenai Upah Minimum Regional DKI Jakarta hal ini dilakukan agar dalam proses implementasi dengan fuzzy mempunyai dasar penetapan ukuran pendapatan minimum dan maksimum pendapatan orang tua mahasiswa.

\subsubsection{Data Questioner}

Data pertanyaan pendapatan orang tua yang sudah didapat dari Mahasiswa selanjutnya di lakukan memasukan data kedalam microsoft excel untuk mengelompokan data yang sudah didapat.

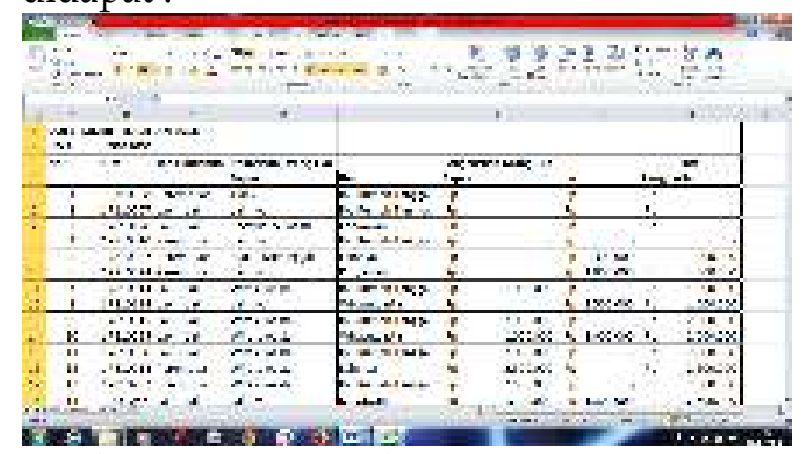

Gbr 4.1 : Data Pendapatan Orang Tua Mahasiswa

\subsubsection{UMR DKI JAKARTA}

Sesuai keputusan Gubernur DKI Jakarta tahun 2017 maka UMR DKI Jakarta tahun 2018 menjadi RP.3.648.035, Informasi ini nantinya akan dijadikan sebagai tolak ukur dalam proses penetapan domain pada penyelesain dengan fuzzy logic.

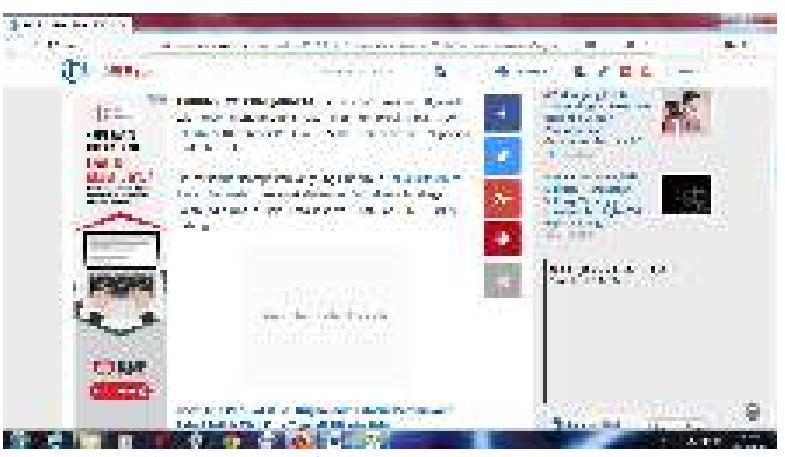

Gbr 4.2 : Infomasi UMR 2018

(Sumber :

http://www.tribunnews.com/metropolit an/2017/11/01/ump-dki-jakarta-tahun-

2018-ditetapkan-sebesar-rp-36-juta )

\subsection{Logika Fuzzy}

Setelah semua data terkumpul maka akan dilakukan penentuan domain dan penggunaan kurva yang akan digunakan dalam penyelesaian dengan fuzzy logic.

\section{a. Variabel Fuzzy}

Variabel fuzzy yang akan digunakan adalah variabel pendapatan orang tua mahasiswa

b. Himpunan Fuzzy

Himpunan yang dibentuk adalah himpunan pendapatan yang digunakan dalam penelitian adalah Rendah, Sedang dan Tinggi, penentuan variabel ini berkaitan erat dengan penentuan Domain

c. Semesta Pembicaraan

Semesta pembicaraan pada penelitian ini akan berhubungan dengan nilai dalam jutaan

d. Domain Pendapatan

Pada penelitian yang dilakukan maka penulis menentukan domain yang dihasilkan dari data yang telah di kumpulkan domain yang dihasilkan adalah sebagai berikut : 
JURNAL PUBLIPRENEUR: POLITEKNIK NEGERI MEDIA KREATIF Vol.6, No. 1, Juni 2018, Doi: https://doi.org/.xxxxx, hal. 18-25

Rendah $=\left[\begin{array}{ll}0 & 5 j t\end{array}\right]$, Sedang $=$ $[3,5 J t$ 7,5Jt], Tinggi $=[5 J t \infty]$

\subsection{Representasi Kurva Segitiga}

Dalam penelitian ini digunakan representasi kurva segitiga dimana dalam prosesnya akan menentukan derajat keanggotaan dari masing - masing orang total pendapatan orang tua mahasiswa sehingga dapat dilihat masuk dalam himpunan manakah pendapatan orang tua sesuai dengan data yang telah dikumpulkan.

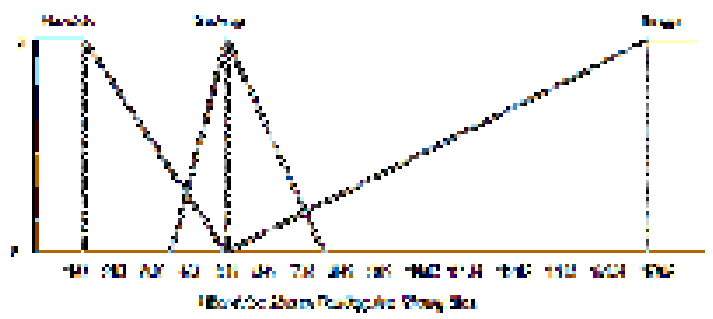

\subsubsection{Derajat Keanggotaan}

Untuk menentukan derajat keanggotaan maka setiap total pendapatan per individu yang ada pada data akan di tentukan sesuai dengan rumus pencarian derajat keanggotaan sesuai dengan representasi kurva yang digunakan. Berikut akan disajikan penghitungan derajat keanggotaan dengan 3 data yang tersedia :

4.3.1.1 Derajat Keanggotaan Rendah (0 $5 \mathrm{Jt})$

Pada derajat keanggotaan rendah dengan menggunakan representasi linear turun maka rumus yang digunakan adalah sebagai berikut, data pendapatan yang digunakan dalam perhitungan adalah $R p 1.500 .000$ :

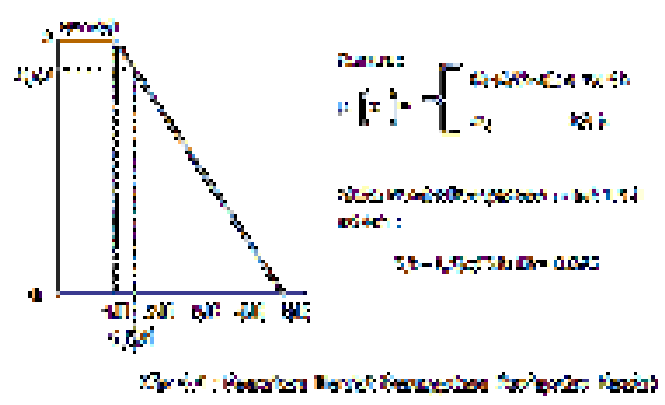

4.3.1.2 Derajat Keanggotaan, Sedang (3,5 $-7,5 \mathrm{Jt})$

Pada derajat keanggotaan sedang dengan menggunakan representasi kurva segitiga maka rumus yang digunakan adalah sebagai berikut, data pendapatan yang digunakan dalam perhitungan adalah Rp4.000.000:

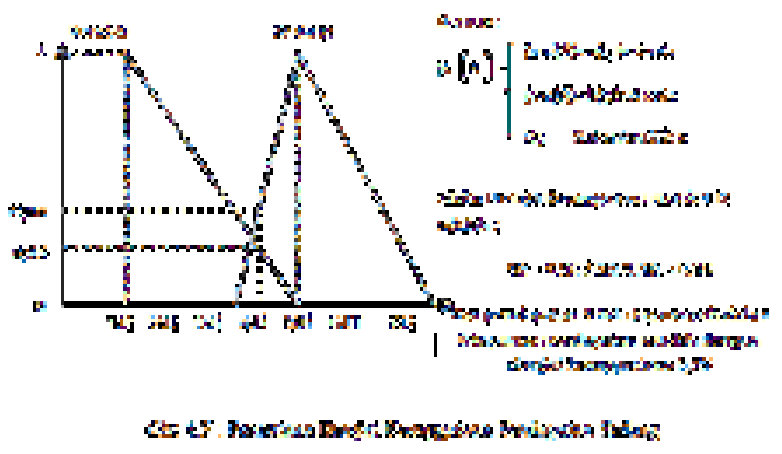

4.3.1.3 Derajat Keanggotaan, Tinggi (5 $\infty \mathbf{J t})$

Pada derajat keanggotaan sedang dengan menggunakan representasi kurva segitiga maka rumus yang digunakan adalah sebagai berikut, data pendapatan yang digunakan dalam perhitungan adalah Rp7.500.000: 
JURNAL PUBLIPRENEUR: POLITEKNIK NEGERI MEDIA KREATIF

Vol.6, No. 1, Juni 2018, Doi: https://doi.org/.xxxxx, hal. 18-25

Accepted: 30 Juni 2018

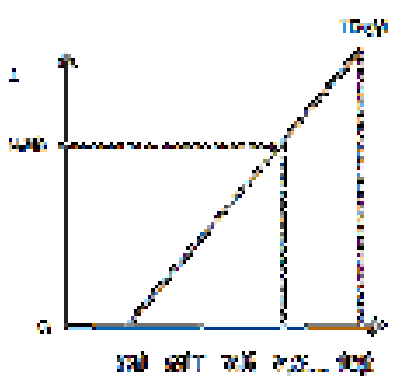

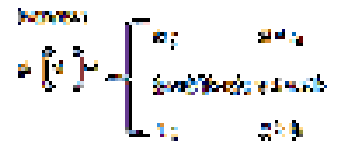

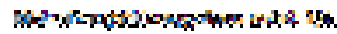
olint: 1

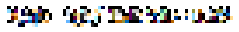

\subsection{Hasil Perhitungan}

Derajat Keanggotaan merupakan identifikasi salah satu data yang ada dalam sebuah himpunan dalam hal ini bisa saja seseorang masuk dalam himpunan kurang dan sedang, atau sebaliknya sedang dan tinggi atau memang pendapatannya masuk dalam himpunan sedang, disitulah terlihat lebih dominan ke dalam himpunan manakah orang tua siswa tersebut dari segi pendapatan perbulan, berikut hasil perhitungan yang telah dilakukan menggunakan Excel .

\begin{tabular}{|c|c|c|c|c|}
\hline \multirow{2}{*}{\multicolumn{2}{|c|}{$\begin{array}{r}\text { Total } \\
\text { Penghasilan }\end{array}$}} & \multicolumn{3}{|c|}{ Derajat Keanggotaan } \\
\hline & & Rendah & Sedang & Tinggi \\
\hline \multicolumn{5}{|l|}{$\mathrm{Rp}$} \\
\hline - & & 1 & 0 & 0 \\
\hline \multicolumn{5}{|l|}{$\mathrm{Rp}$} \\
\hline - & & 1 & 0 & 0 \\
\hline \multicolumn{5}{|l|}{$\mathrm{Rp}$} \\
\hline- & & 1 & 0 & 0 \\
\hline \multicolumn{5}{|l|}{$\mathrm{Rp}$} \\
\hline - & & 1 & 0 & 0 \\
\hline $\mathrm{Rp}$ & 300.000 & 1 & 0 & 0 \\
\hline $\mathrm{Rp}$ & 1.000 .000 & 1 & 0 & 0 \\
\hline $\mathrm{Rp}$ & 1.000 .000 & 1 & 0 & 0 \\
\hline $\mathrm{Rp}$ & 1.500 .000 & 0,875 & 0 & 0 \\
\hline $\mathrm{Rp}$ & 2.000 .000 & 0,75 & 0 & 0 \\
\hline $\mathrm{Rp}$ & 2.000 .000 & 0,75 & 0 & 0 \\
\hline
\end{tabular}

\begin{tabular}{|c|c|c|c|c|}
\hline $\mathrm{Rp}$ & 2.000 .000 & 0,75 & 0 & 0 \\
\hline $\mathrm{Rp}$ & 2.500 .000 & 0,625 & 0 & 0 \\
\hline $\mathrm{Rp}$ & 2.500 .000 & 0,625 & 0 & 0 \\
\hline $\mathrm{Rp}$ & 2.600 .000 & 0,6 & 0 & 0 \\
\hline $\mathrm{Rp}$ & 3.000 .000 & 0,5 & 0 & 0 \\
\hline $\mathrm{Rp}$ & 3.000 .000 & 0,5 & 0 & 0 \\
\hline $\mathrm{Rp}$ & 3.000 .000 & 0,5 & 0 & 0 \\
\hline $\mathrm{Rp}$ & 3.100 .000 & 0,475 & 0 & 0 \\
\hline $\mathrm{Rp}$ & 3.200 .000 & 0,45 & 0 & 0 \\
\hline $\mathrm{Rp}$ & 3.500 .000 & 0,375 & 0 & 0 \\
\hline $\mathrm{Rp}$ & 3.500 .000 & 0,375 & 0 & 0 \\
\hline $\mathrm{Rp}$ & 4.000 .000 & 0,25 & 0,333333 & 0 \\
\hline $\mathrm{Rp}$ & 4.000 .000 & 0,25 & 0,333333 & 0 \\
\hline $\mathrm{Rp}$ & 4.000 .000 & 0,25 & 0,333333 & 0 \\
\hline $\mathrm{Rp}$ & 4.000 .000 & 0,25 & 0,333333 & 0 \\
\hline $\mathrm{Rp}$ & 4.000 .000 & 0,25 & 0,333333 & 0 \\
\hline $\mathrm{Rp}$ & 4.000 .000 & 0,25 & 0,333333 & 0 \\
\hline $\mathrm{Rp}$ & 4.000 .000 & 0,25 & 0,333333 & 0 \\
\hline $\mathrm{Rp}$ & 4.500 .000 & 0,125 & 0,6666667 & 0 \\
\hline $\mathrm{Rp}$ & 5.000 .000 & 0 & 1 & 0 \\
\hline $\mathrm{Rp}$ & 5.000 .000 & 0 & 1 & 0 \\
\hline $\mathrm{Rp}$ & 5.000 .000 & 0 & 1 & 0 \\
\hline $\mathrm{Rp}$ & 5.000 .000 & 0 & 1 & 0 \\
\hline $\mathrm{Rp}$ & 5.000 .000 & 0 & 1 & 0 \\
\hline $\mathrm{Rp}$ & 5.000 .000 & 0 & 1 & 0 \\
\hline $\mathrm{Rp}$ & 5.400 .000 & 0 & 0,84 & 0,04 \\
\hline $\mathrm{Rp}$ & 5.500 .000 & 0 & 0,8 & 0,05 \\
\hline $\mathrm{Rp}$ & 5.500 .000 & 0 & 0,8 & 0,05 \\
\hline $\mathrm{Rp}$ & 6.000 .000 & 0 & 0,6 & 0,1 \\
\hline $\mathrm{Rp}$ & 6.300 .000 & 0 & 0,48 & 0,13 \\
\hline $\mathrm{Rp}$ & 6.500 .000 & 0 & 0,4 & 0,15 \\
\hline $\mathrm{Rp}$ & 6.800 .000 & 0 & 0,28 & 0,18 \\
\hline $\mathrm{Rp}$ & 7.000 .000 & 0 & 0,2 & 0,2 \\
\hline $\mathrm{Rp}$ & 7.000 .000 & 0 & 0,2 & 0,2 \\
\hline $\mathrm{Rp}$ & 7.000 .000 & 0 & 0,2 & 0,2 \\
\hline $\mathrm{Rp}$ & 7.500 .000 & 0 & 0 & 0,25 \\
\hline $\mathrm{Rp}$ & 8.000 .000 & 0 & 0 & 0,3 \\
\hline $\mathrm{Rp}$ & 8.800 .000 & 0 & 0 & 0,38 \\
\hline $\mathrm{Rp}$ & 9.000 .000 & 0 & 0 & 0,4 \\
\hline $\mathrm{Rp}$ & 11.000 .000 & 0 & 0 & 0,6 \\
\hline
\end{tabular}

e-ISSN 2723-6323

p-ISSN 2338-5049 
JURNAL PUBLIPRENEUR: POLITEKNIK NEGERI MEDIA KREATIF

Vol.6, No. 1, Juni 2018, Doi: https://doi.org/.xxxxx, hal. 18-25

Submitted: 12 April 2018

Revised: 13 Mei 2018

- Accepted: 30 Juni 2018

\begin{tabular}{|rr|r|r|r|}
$\mathrm{Rp}$ & 12.000 .000 & 0 & 0 & 0,7 \\
\hline $\mathrm{Rp}$ & 12.000 .000 & 0 & 0 & 0,7 \\
\hline $\mathrm{Rp}$ & 12.000 .000 & 0 & 0 & 0,7 \\
\hline $\mathrm{Rp}$ & 14.500 .000 & 0 & 0 & 0,95 \\
\hline $\mathrm{Rp}$ & 15.000 .000 & 0 & 0 & 1 \\
\hline $\mathrm{Rp}$ & 15.000 .000 & 0 & 0 & 1 \\
\hline $\mathrm{Rp}$ & 20.000 .000 & 0 & 0 & 1 \\
\hline $\mathrm{Rp}$ & 30.000 .000 & 0 & 0 & 1 \\
\hline
\end{tabular}

Tbl 4.1 : Hasil perhitungan berdasarkan derajat keanggotaan

Dan dari hasil yang didapat adalah Sebagai Berikut :

a) Orang tua dengan pendapatan Kurang sebanyak $=21$ orang

b) Orang tua dengan pendapatan kurang tetapi cenderung sedang $=$ 8 Orang

c) Orang tua dengan pendapatan sedang $=6$ Orang

d) Orang tua dengan pendapatan sedang tetapi masuk tinggi $=10$ Orang

e) Orang tua dengan pendapatan tinggi $=13$ Orang

Dari hasil penelitian terlihat bahwa sekitar $36,20 \%$ pendapatan orang tua siswa masuk dalam kategori rendah sedangkan $63,79 \%$ adalah sedang dan tinggi

\subsection{Hasil dalam Grafik Excel}

Pada penelitian ini juga membuat grafik pada excel berdasarkan data dan perhitungan yang telah dibuat, yang bertujuan apakah dengan menggunakan fuzzy bisa di transformasikan dengan bentuk grafik pada Microsoft Excel .

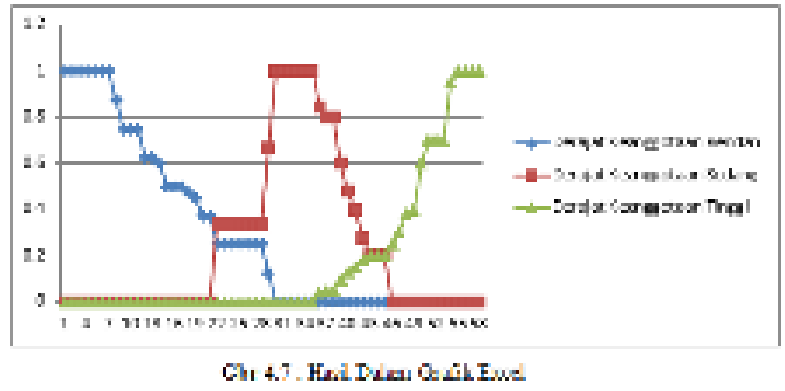

\section{KESIMPULAN DAN SARAN}

Dari kegiatan penelitian yang dilakukan maka dapat diambil beberapa kesimpulan yang diharapkan dapat memberikan sebuah gambaran penyelesaian suatu masalah dengan metode kecerdasan buatan dalam hal ini logika fuzzy

\subsection{Kesimpulan}

Kesimpulan dari hasil yang didapat dari penelitian yang dilakukan di Politeknik Negeri Media Kreatif adalah sebagai berikut :

1. Dengan menggunakan logika fuzzy maka dapat terlihat bagaimana tingkat pendapatan dari masing - masing orang tua mahasiswa dan pengkategorian tingkat pendapatan dalam logika fuzzy tidak bersifat mutlak dimana ada juga sisi pertimbangan dimana orang tua siswa tersebut dapat dikatakan berpendapatan sedang walaupun masuk juga dalam kategori berpendapatan rendah, dan penilaiannya dapat dilihat dari derajat keanggotaan himpunan fuzzy.

2. Dalam penyelesaian dengan logika fuzzy menghasilkan sebuah informasi yang lebih rinci dan dapat dijadikan sebuah pengambilan keputusan bagi institusi dalam menentukan tingkat kehidupan ekonomi mahasiswa. 
